\title{
Automatic Identification of Alpine Mass Movements by a Combination of Seismic and Infrasound Sensors
}

\author{
Andreas Schimmel ${ }^{1, *(1)}$, Johannes Hübl ${ }^{1}$, Brian W. McArdell ${ }^{2}$ and Fabian Walter ${ }^{3}$ \\ 1 Institute of Mountain Risk Engineering, University of Natural Resources and Life Sciences (BOKU), \\ 1190 Vienna, Austria; johannes.huebl@boku.ac.at \\ 2 Swiss Federal Institute for Forest, Snow and Landscape Research WSL, 8903 Birmensdorf, Switzerland; \\ brian.mcardell@wsl.ch \\ 3 Laboratory of Hydraulics, Hydrology and Glaciology (VAW), ETH Zürich, 8093 Zürich, Switzerland; \\ walter@vaw.baug.ethz.ch \\ * Correspondence: andreas.schimmel@boku.ac.at; Tel.: +43-1-47654-87131
}

Received: 18 April 2018; Accepted: 5 May 2018; Published: 22 May 2018

\begin{abstract}
The automatic detection and identification of alpine mass movements such as debris flows, debris floods, or landslides have been of increasing importance for devising mitigation measures in densely populated and intensively used alpine regions. Since these mass movements emit characteristic seismic and acoustic waves in the low-frequency range $(<30 \mathrm{~Hz})$, several approaches have already been developed for detection and warning systems based on these signals. However, a combination of the two methods, for improving detection probability and reducing false alarms, is still applied rarely. This paper presents an update and extension of a previously published approach for a detection and identification system based on a combination of seismic and infrasound sensors. Furthermore, this work evaluates the possible early warning times at several test sites and aims to analyze the seismic and infrasound spectral signature produced by different sediment-related mass movements to identify the process type and estimate the magnitude of the event. Thus, this study presents an initial method for estimating the peak discharge and total volume of debris flows based on infrasound data. Tests on several catchments show that this system can detect and identify mass movements in real time directly at the sensor site with high accuracy and a low false alarm ratio.
\end{abstract}

Keywords: infrasound sensors; seismic sensors; debris flow; detection system; identification system

\section{Introduction}

As described by [1], debris flows are highly concentrated mixtures of water and fine and coarse sediments, often containing additional woody debris, with front velocities of up to $20 \mathrm{~m} / \mathrm{s}$. The coarse sediment is usually concentrated in the upper layers and at the front of the flow, and the sediment concentration is often between $40 \%$ and $70 \%$ by volume with a specific bulk density of $1.7-2.4 \mathrm{~g} / \mathrm{cm}^{3}$. Mudflows are similar to debris flows, but have a smaller concentration of boulders and more fine material [2]. Debris floods have higher water content and a finer sediment concentration in comparison to debris flows. Compared to debris flows and debris floods, bedload transport processes have no defined front and also have a greater water content.

Due to the fast socio-economic development of mountain areas, processes such as debris flows, debris floods, and bedload transport constitute an increasing hazard to lives and property. Monitoring debris flow torrents is essential for warning purposes and for gaining more knowledge about the processes. The fact that such mass movements emit seismic and acoustic waves in the low-frequency range $(<30 \mathrm{~Hz})$ enables detection of these events from a safe location unaffected by the process. Consequently, several approaches for detection and warning systems based on seismic or infrasound signals have already been developed. 
The main source of seismic energy delivered by debris flows is the basal friction of the dense body of the flow in contact with the channel bed and boundaries (e.g., [3,4]). Seismic signals are less affected by wind and weather than are infrasound signals, but they have a strong dependency on the modulus (stiffness) of the ground and the distance between channel and sensor [5]. The monitoring of mass movements with geophones or seismometers is quite common [6-9] and a range of detection systems based on seismic signals has already been designed (e.g., [10-12]).

Infrasound waves are produced by the turbulent flow part of the mass movement $[13,14]$. These acoustic waves are detectable over large distances (several $\mathrm{km}$ ) due to the frequency-dependency of atmospheric attenuation, which absorbs high-frequency (audible and ultra-) sound more than infrasound $(<20 \mathrm{~Hz})[15])$. Infrasound signals produced by mass movements are generally in a relatively noise-free band in the low-frequency acoustic spectrum $(\leq 20 \mathrm{~Hz})$ where the main noise is induced by wind [16]. Several detection systems for sediment-related transport processes based on infrasound signals have been developed $[17,18]$, although these methods are less common than those based on seismic signals.

Since both seismic and infrasonic mass movement monitoring have benefits and drawbacks, research on the combining of both technologies has been conducted in recent years. Both [19] and [16] show the correlation between seismic and infrasound signals from avalanches and debris flows and [20] analyzed the signal pattern of both for debris flows and how they can be used for a detection method.

For the identification of an event, different methods for signal classification have already been analyzed. An approach was developed by [21] for seismic detection of snow avalanches based on the fusion of data derived from the analysis of the signal in three domains: time, time frequency and polarizations. A database of observed avalanches was used by [22] to derive ten characteristic parameters that are determined from the time series and power spectrum. These parameters are used for automatic detection. The Hilbert-Huang transform (HHT) approach was applied by [17] to analyze the infrasound and geophone signals induced by debris flows.

This paper describes an extension of the already published approach for an early warning system based on the combination of seismic and infrasound sensors [23]. The recorded signals are automatically analyzed by a detection algorithm in order to identify events in real time as soon as possible, while at the same time reducing the number of false detections. We present updates made in the new version of the detection algorithm and we provide a deeper insight into the hardware setup and software design. Since the number of test sites has nearly doubled in recent years, we now can present the detection results from a large number of new recorded events and analyze the possible average early warning times of this system. Furthermore, an evaluation of the possibility to estimate the discharge based on infrasound or seismic signals has been carried out, and we present here a method to estimate the peak discharge and the total volume of an event based on infrasound signals.

\section{Detection System}

This section will describe the updates made on the detection system presented in [23] and will give a deeper insight into the hardware and software design. The basic setup of a combination of one seismic and one infrasound sensor together with a microcontroller has not been modified, but the detection algorithm has been updated and new sensors has been tested. As already mentioned in $[23,24]$, this system is low cost and easy to install, so that it can be extended to a warning system for different applications: safeguarding of traffic routes by controlling traffic lights, protection of construction sites inside torrents (e.g., for cleaning up a basin after an event), or at sites where the necessary funding for expensive torrent and avalanche barriers is not available.

\subsection{Hardware Setup}

Three different infrasound sensors and two different geophones are used for the current setup. An example of an infrasound sensor used at three test sites is the Chaparral Model 24 (Chaparral Physics, Fairbanks, AK, USA), which has a sensitivity of $2 \mathrm{~V} / \mathrm{Pa}$ and a frequency range from 0.1 to 
$200 \mathrm{~Hz}$. As a second sensor, we use the infrasound microphone MK-224 with a frequency range from $3 \mathrm{~Hz}$ to $200 \mathrm{~Hz}$ and a sensitivity of $50 \mathrm{mV} / \mathrm{Pa}$. Both sensors had already been used in [23] but proved to be rather expensive. Thus, a cheaper alternative was found with an Electret microphone of the type KECG2742WBL-25-L (Kingstate Electronics Corp., Taipei Hsien, Taiwan). Due to the use of this microphone, the overall system costs can be reduced by a factor of six compared to the system cost using a Chaparral sensor. The Electret microphone has a sensitivity of $-38 \mathrm{~dB} \pm 3 \mathrm{~dB}$ in the frequency range used, which results in approximately $13 \mathrm{mV} / \mathrm{Pa}$ and a typical frequency range of $20 \mathrm{~Hz}$ to $20 \mathrm{kHz}$. Because we use this microphone below $20 \mathrm{~Hz}$ and it has a large variation in sensitivity, it has to be calibrated, which is done by comparing the signal with the Chaparral Model 24. As seismic sensors, we use the Sensor NL SM-6 (ION, Leiden, The Netherlands) with a sensitivity of $28.8 \mathrm{~V} / \mathrm{m} / \mathrm{s}$ and a natural frequency of $4.5 \mathrm{~Hz}$ in addition to the Sercel SG-5 geophone (Sercel Inc., Houston, TX, USA) used formerly with a sensitivity of $80 \mathrm{~V} / \mathrm{m} / \mathrm{s}$ and a natural frequency of $5 \mathrm{~Hz}$.

The sensor signals have to be adapted for the input of the microcontroller, which is done by a non-inverting OPV circuit (except for the Chapperal Model 24, where an inverting OPV circuit is used). This input circuit also has a band pass filtering with a lower cut-off frequency of around $150 \mathrm{mHz}$ (for acoustic sensors) and an upper cut-off frequency of $150 \mathrm{~Hz}$ (acoustic and seismic sensors) included. These input signals are sampled by the microcontroller ADC (analog-to-digital converter) with a sample rate of $100 \mathrm{~Hz}$, whereby a $32 \times$ hardware oversampling is used to avoid aliasing. A Stellaris Evaluation Board with the microcontroller LM3S8962 (Luminary Micro Inc., Austin, TX, USA) is used for the data processing and as data-logger. This microcontroller is based on the 32-bit ARM Cortex-M3 architecture with a processor frequency of $50 \mathrm{MHz}, 64 \mathrm{~KB}$ RAM and a Flash storage of $256 \mathrm{~KB}$. The evaluation board has four ADCs, two UARTs (Universal Asynchronous Receiver Transmitters), several GPIOs (general purpose input/output), which can be used as alarm outputs, and an OLED (organic light emitting diode) display and offers the possibility of an Ethernet connection. The data can be stored on a micro SD card where up to four months of data can be recorded continuously on a 16 GB card with the file structure as described in Section 2.2. Besides the input of the sensor signals, the free ADCs offer the possibility to log the flow height measured by a radar or ultrasonic gauge, which can be used for event verification. In addition, the power supply voltage can be measured to check for low power situations. If the test site is equipped with a standard internet connection, the communication with the system can be conducted via the Ethernet interface. If there is no router available, we use a GSM module of the type SparqEE CELLv1.0 [25], which is controlled by means of UART by AT commands. The time synchronization of the station is done by either a connection with a time server via Ethernet, or by a GPS module, which is also connected via the UART. An overview of the hardware components and the inputs and outputs of the system is given in Figure 1.

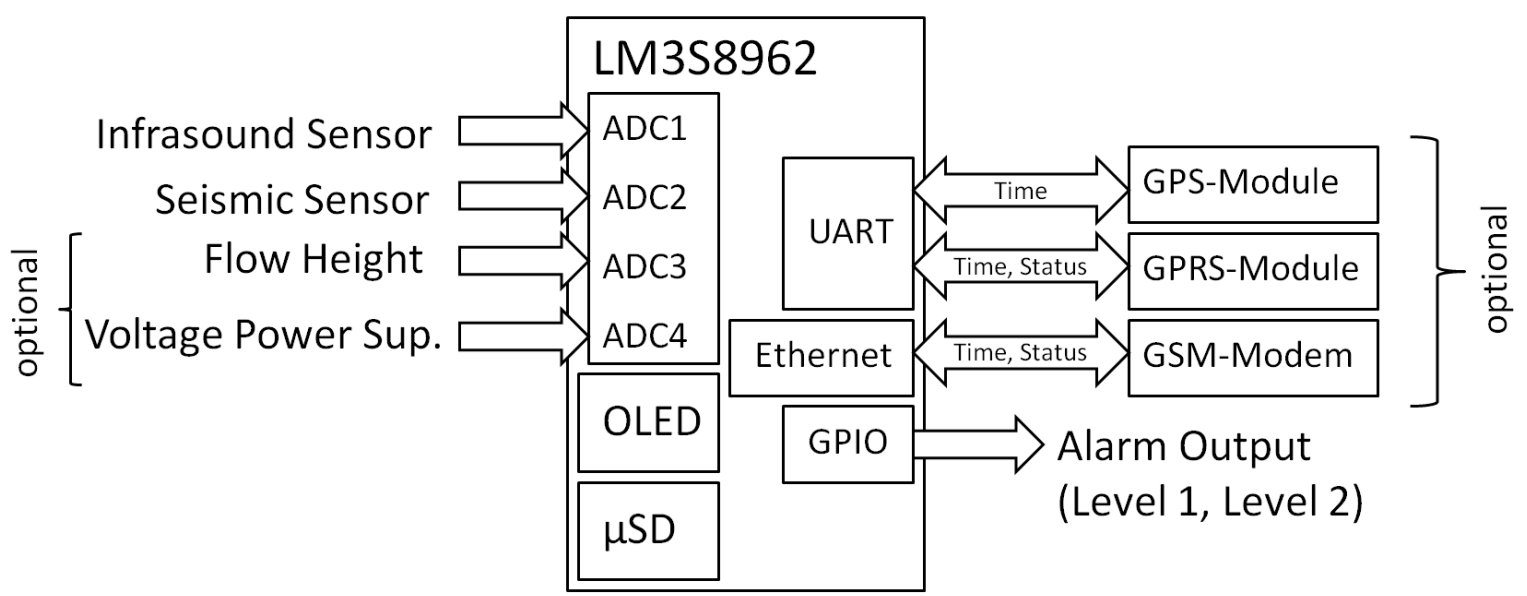

Figure 1. Overview system setup and components. 
The LM3S8962 operates at a voltage of $5 \mathrm{~V}$, provided by a DC-DC converter, which needs a power connection at a voltage range from 6.5 to $32 \mathrm{~V}$. The system has a power consumption below $1.5 \mathrm{~W}$, which makes this system very useful for stand-alone stations using a solar power supply, as is typically used. The minimum solar power supply designed for this system should be based on a $12 \mathrm{Wp}$ solar panel and a 16 Ah battery. This specification might have to be adapted due to sun availability or communication setup.

\subsection{Software Design}

The software for the microcontroller was written in $C$ and is based on the open source runtime system FreeRTOS [26]. FreeRTOS offers the possibility to create several tasks with different priorities and cycling times. Six different tasks are used for this system: the task with the highest priority is the measurement task, where the input signals are sampled at a sample rate of $100 \mathrm{~Hz}$, and then converted and stored in an array. This array offers the input for the detection task, which is executed every second. This detection task is responsible for the signal processing (fast Fourier transform (FFT)) and runs the detection algorithm described in Section 2.3. For the storage of the data to the micro SD card, a log task is run every second. Three different files are created by this task: the raw data of the infrasound and seismic sensor are written into one text file and the output of the detection algorithm and ancillary data, such as flow height measured with an additional sensor and power supply voltage, are written in another file. Both files are created every hour. Another file stores a summary of all $\log$ files, and displays event detections or errors. A time task is created for the control of the system time. A control task regulates the alarm outputs, the point in time for output messages and time synchronization, and reacts to the inputs from the evaluation board keys. The output messages and the time synchronization are done as part of a communication task where the Ethernet connection is used via LWIP (light-weight implementation of the TCP/IP protocol) or the GSM module is controlled via UART. The system is designed to send a status message to a server every hour, whereby the date of the event detections or error messages are included. This server creates e-mail alerts in the case of an event. A web server is installed on this server as well, where the status and events at all stations can be checked [27]. Table 1 shows a list of the tasks performed, cycling time and their priorities in the FreeRTOS runtime.

Table 1. FreeRTOS tasks.

\begin{tabular}{cccc}
\hline Task Name & Description & Priority & Time Interval \\
\hline Measurement Task & Receives signals from ADC & 6 (highest) & $10 \mathrm{~ms}$ \\
Detection Task & Calculates FFT, execute detection algorithm & 5 & $1 \mathrm{~s}$ \\
Time Task & Controls system time & 4 & $1 \mathrm{~s}$ \\
Log Task & Data logging to SD card & 3 & $1 \mathrm{~s}$ \\
Control Task & Controls outputs and points in time for com. & 2 & $1 \mathrm{~s}$ \\
COM Task & Communication via Ethernet or UART & 1 (lowest) & $1 \mathrm{~s}$ (on demand) \\
\hline
\end{tabular}

\subsection{Detection Algorithm}

Based on the results at the test sites, the detection algorithm presented earlier in [23] has been modified to increase the detection probability and reduce the frequency of false alarms. This section will give a short summary of the (new) detection algorithm and its different criteria.

As the former version, the input signals that are sampled with $100 \mathrm{~Hz}$ are processed by fast Fourier transform (Bluestein FFT algorithm [28]) with 100 samples every second, and different frequency bands of the infrasound and seismic signals have to fulfill several detection criteria for a specific time span (detection time). Three different criteria are applied to the infrasound signal: for the first criterion, the average amplitude of a debris flow $\left(\bar{A}_{\text {DFlow }}\right)$ or debris flood $\left(\bar{A}_{\text {DFlood }}\right)$ frequency band has to exceed a threshold for the detection time. We use two different frequency bands for debris flow $(3-15 \mathrm{~Hz})$ and debris flood signals $(15-45 \mathrm{~Hz})$ because the peak frequency of the infrasound signals depends on 
the viscosity of the event (e.g., [16]). Thus, these two frequency bands represent the typical signals of debris flows and debris floods and can be used for process-type identification. Two limits are used to distinguish between different event sizes. Detections fulfilling the Level 1 threshold $A_{\text {LimitL1 }}$ are mostly higher discharge with sediment transport or small debris floods; event detections at Level 2 (threshold $A_{\text {LimitL2 }}$ ) are typically "fully developed" debris flows and debris floods:

$$
\begin{aligned}
& \text { Level 1: } \bar{A}_{\text {DFlow }} \geq A_{\text {LimitL1 }} \text { or } \bar{A}_{\text {DFlood }} \geq A_{\text {LimitL1, }} \\
& \text { Level 2: } \bar{A}_{\text {DFlow }} \geq A_{\text {LimitL2 }} \text { or } \bar{A}_{\text {DFlood }} \geq A_{\text {LimitL2 }} .
\end{aligned}
$$

As a second criterion, the average infrasound amplitudes of the debris flow or debris flood frequency band have to be at least above a third (for debris flows) or a fourth (for debris floods) of the amplitudes of the frequency band below $\left(\bar{A}_{\text {low }}\right)$ :

$$
\bar{A}_{\text {DFlow }}>\frac{\bar{A}_{\text {low }}}{3} \text { or } \bar{A}_{\text {DFlood }}>\frac{\bar{A}_{\text {low }}}{4} .
$$

These criteria serve mainly to prevent false alarms due to wind that dominates this low-frequency band. The wind-produced amplitudes in this low-frequency band ( $\leq 2 \mathrm{~Hz})$ are usually at least three times higher than the amplitudes in the debris flow frequency band and at least four times higher than the amplitudes in the debris flood frequency band. In the former version [23,29], a higher frequency band was also used, whose amplitudes had to be lower than the debris flow/debris floods bands' amplitudes. Because debris floods with higher peak frequencies have not been detected by the algorithm including this criterion, it has been omitted and a greater detection time was chosen in place of this criterion.

The variance in amplitudes in the debris flow or debris flood frequency band is used by the third criterion of the detection algorithm. Since this variance in the amplitudes of the broad-banded debris flow or debris flood signals is low, compared to narrow-banded signals from artificial sources (such as aircrafts, cars, machines, etc.), this criterion efficiently reduces the frequency of artificially caused false alarms. Therefore, the variance in the amplitude $A_{\text {VarIS }}$ has to be under a certain limit $\left(A_{\text {VarLimit }}\right)$ :

$$
A_{\text {VarIS }} \leq A_{\text {VarLimit }}
$$

Only the amplitude and the variance criteria are used for the seismic signals. Since the dependency of peak frequencies on the viscosity is not as significant as for infrasound signals, only one frequency band is used for debris flows and also for debris floods $\left(\bar{A}_{\text {DFlow/DFlood }}\right)$. For the classification of the event size, two different limits $\left(A_{\text {LimitL1 }}, A_{\text {LimitL2 }}\right)$ are also used:

$$
\begin{gathered}
\text { Level 1: } \bar{A}_{\text {DFlow } / \text { DFlood }} \geq A_{\text {LimitL1, }} \\
\text { Level 2: } \bar{A}_{\text {DFlow } / \text { DFlood }} \geq A_{\text {LimitL2, }} \\
\qquad A_{\text {VarGEO }} \geq A_{\text {VarLimit }} .
\end{gathered}
$$

Because bedload transport processes as well as debris flows and debris floods can be detected, a further criterion is needed to enable identification of event type. Debris flows and debris floods typically occur in several surges and have a well-defined front compared to bedload transport (e.g., [30]), so these event types can be identified by a rapid rise in the seismic or infrasound signal. For debris flow/debris flood detection, the seismic amplitude has to rise at least beyond the threshold used for the amplitude criterion during the detection time, whereby we also distinguish between Level $1\left(A_{\text {LimitL1 }}\right)$ and Level $2\left(A_{\text {LimitL2}}\right)$ detections. Because the signal sequence of the seismic amplitudes is smoother than that of the infrasound signals, we use seismic amplitudes for this identification criterion. 
These criteria have to be fulfilled for the infrasound as well as for the seismic signals for the detection time threshold of $20 \mathrm{~s}$ to trigger an event detection. Several actions of the warning system can be started based on the two alarm levels (e.g., SMS alert, control of a traffic light, etc.), depending on the application. With the combination of the seismic and infrasound signals, we achieve a high detection ratio and a strong reduction in the frequency of false alarms. For example, at the Gadria test site in South Tyrol in 2016, the system would register more than one hundred false alarms if either the infrasound or the seismic data were used alone. By combining both technologies, and applying all criteria, the false alarms can be reduced to only two. If we omit the wind criterion (Equation (3)), the false alarms will double, and if we omit the variance criterion (Equation (4)), the false alarms will increase to 21 (Figure 2).

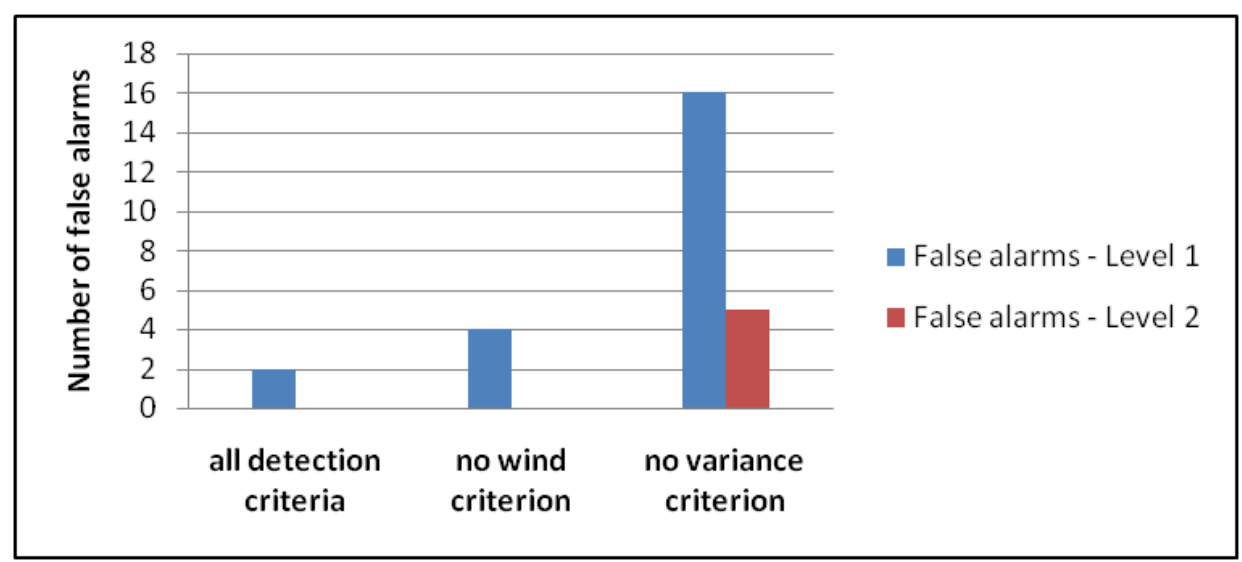

Figure 2. Effect of the different detection criteria on the false alarms at the Gadria test site in 2016.

The parameters of the detection algorithm (Table 2) have been identified in an exhaustive evaluation and optimization process and show good results at all test sites. Compared to the first version presented in [23], we have adjusted the frequency bands of the infrasound signals in the low-frequency range to ensure better detection of extremely viscous debris flows that have their peak amplitudes in a low frequency range $(<5 \mathrm{~Hz},[31])$. Furthermore, the upper limit for the debris flood frequency band has been increased to enable better detection of certain debris floods with higher peak frequencies. For further applications of the system, the parameters can be adapted to special requirements of the site, application and the background noise.

Table 2. Current settings for the detection algorithm.

\begin{tabular}{|c|c|c|c|}
\hline & & Infrasound Signal & Seismic Signal \\
\hline Frequency band 1 & $F B 1_{\text {low }}-F B 1_{\text {high }}$ & 1 to $2 \mathrm{~Hz}$ & - \\
\hline Frequency band 2-debris flow & $F B 2_{\text {low }}-F B 2_{\text {high }}$ & 3 to $15 \mathrm{~Hz}$ & 10 to $30 \mathrm{~Hz}$ \\
\hline Frequency band 3-debris flood & $F B 3_{\text {low }}-F B 3_{\text {high }}$ & 15 to $45 \mathrm{~Hz}$ & 10 to $30 \mathrm{~Hz}$ \\
\hline Limit for Amplitudes_-Level 1 & $A_{\text {LimitL1 }}$ & $12 \mathrm{mPa}$ & $1 \mu \mathrm{m} / \mathrm{s}$ \\
\hline Limit for Amplitudes-Level 2 & $A_{\text {LimitL1 }}$ & $30 \mathrm{mPa}$ & $2 \mu \mathrm{m} / \mathrm{s}$ \\
\hline Limit for Variance & $A_{\text {VarLimit }}$ & \multicolumn{2}{|l|}{0.8} \\
\hline Time span for detection & $T_{\text {det }}$ & \multicolumn{2}{|l|}{$20 \mathrm{~s}$} \\
\hline
\end{tabular}

\section{Test Sites}

Over the past several years, several torrent catchments have been instrumented with the detection system described here (Figure 3). The Tyrolese torrents Lattenbach, Dristenau and Farstrinne [23] and the Schüsserbach in Styria were equipped with the system during the period from 2013 to 2016. The system was operational in 2013, 2015 and 2016, at the eastern Tyrolese test site Wartschenbach. 
The system has been running at Illgraben, Gadria and Marderello catchments since 2015, and the Bavarian Lueger Hausgraben torrent was equipped with the system in summer 2016.

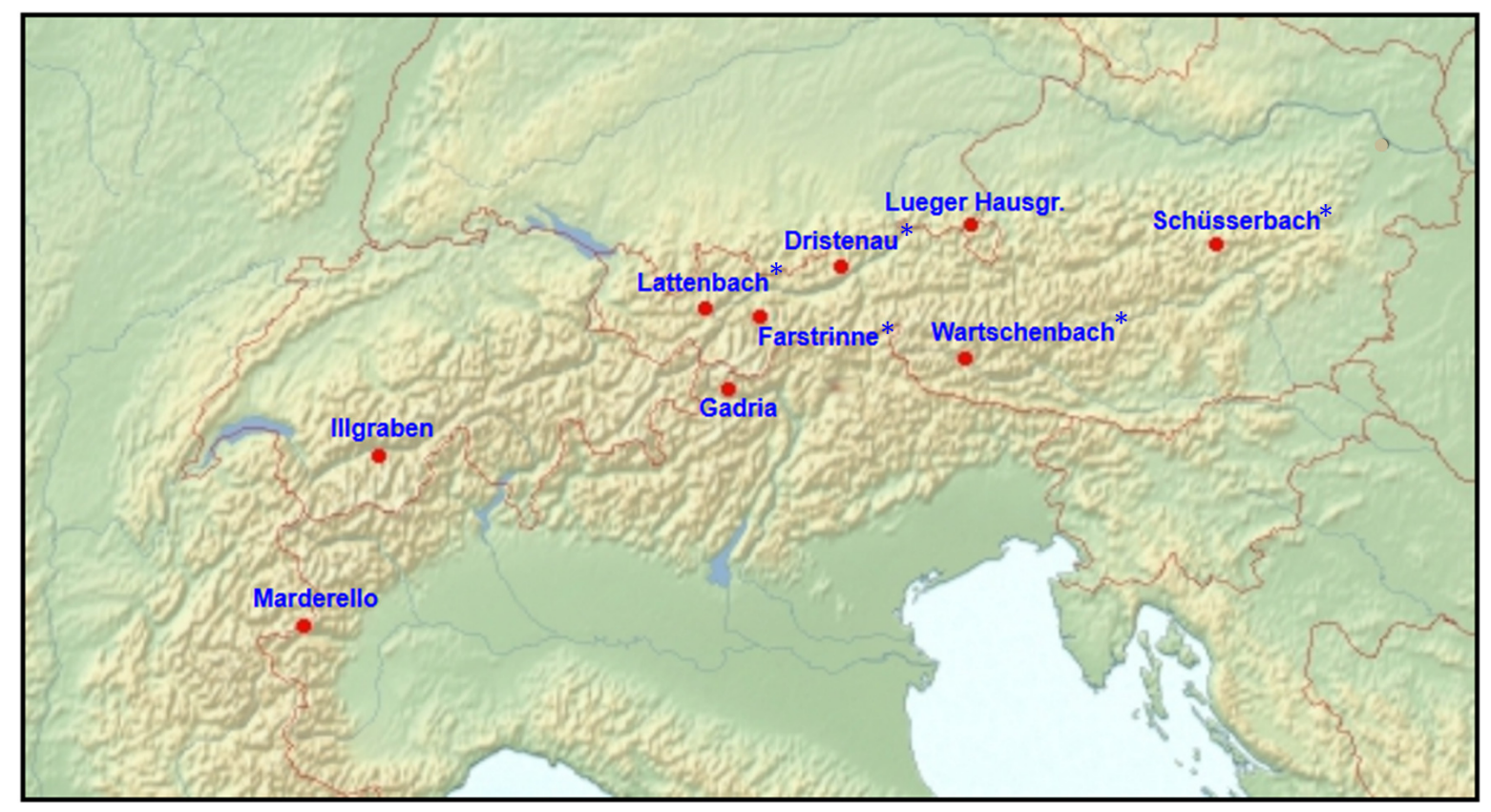

Figure 3. Overview of the test sites from 2013 to 2016 (* test sites already presented in [23]).

The following section describes two examples of event detection at the Marderello and Illgraben test site.

\section{Example Events}

\subsection{Marderello}

The Marderello catchment is located in the northwestern Italian Alps in the eastern part of the Cenischia valley. It has a catchment area of $6.61 \mathrm{~km}^{2}$, and the upper basin altitude is at $3538 \mathrm{~m}$ a.s.1. at the Rocciamelone Mt., extending down to the village of Novalesa at an altitude of $900 \mathrm{~m}$ a.s.1., with an average slope gradient of $60 \%$. Due to its geomorphic conditions [32], frequent mudflows and debris flow events occur in this catchment. Initial monitoring activities began in 1994, and, in 2013, the monitoring system was improved. It is now equipped with one ultrasonic gauge for flow depth measuring, two video cameras and four geophones [33]. In the year 2015, the detection system based on an infrasound and a seismic sensor was installed in the lower part of the catchment close to the indicated monitoring Station 1 (Figure 4). A Chaparral Model 24 infrasound sensor and a Sercel SG-5 geophone were installed.

A mudflow at Marderello was recorded on 9 August 2015 beginning at 2:00 p.m. The total discharge of this mudflow was approximately $50,000 \mathrm{~m}^{3}$ with an event duration of around $4500 \mathrm{~s}$. The infrasound and seismic signals of this event are shown in Figure 5. A significant feature of this event is the high amplitudes of the infrasound signal in the low frequency range $(<5 \mathrm{~Hz})$ between 2800 and $4400 \mathrm{~s}$, while the seismic amplitudes are rather low in this time window. We assume that this phenomenon was due to the joint effect of (i) the passing of the mudflow at the waterfall in the upper area, between 3000 and $3500 \mathrm{~s}$ and (ii) the very low velocity during the first half of the flow, between 3500 and $4500 \mathrm{~s}$. Waterfall-produced infrasound has been identified with peak frequencies below $5 \mathrm{~Hz}$ [34], and a possible misleading effect of the Marderello waterfall on the seismic signal was already observed for previous events [11]. 

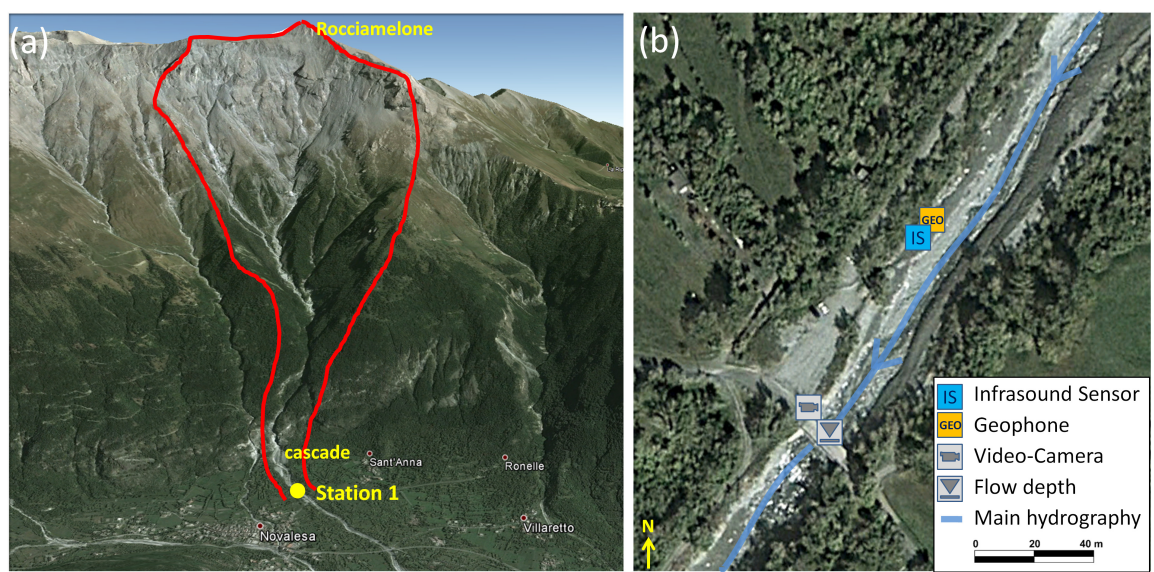

Figure 4. (a) overview of the test site Marderello (red line: catchment area); (b) closer view of the monitoring station and sensor setup (Source: Google Maps).
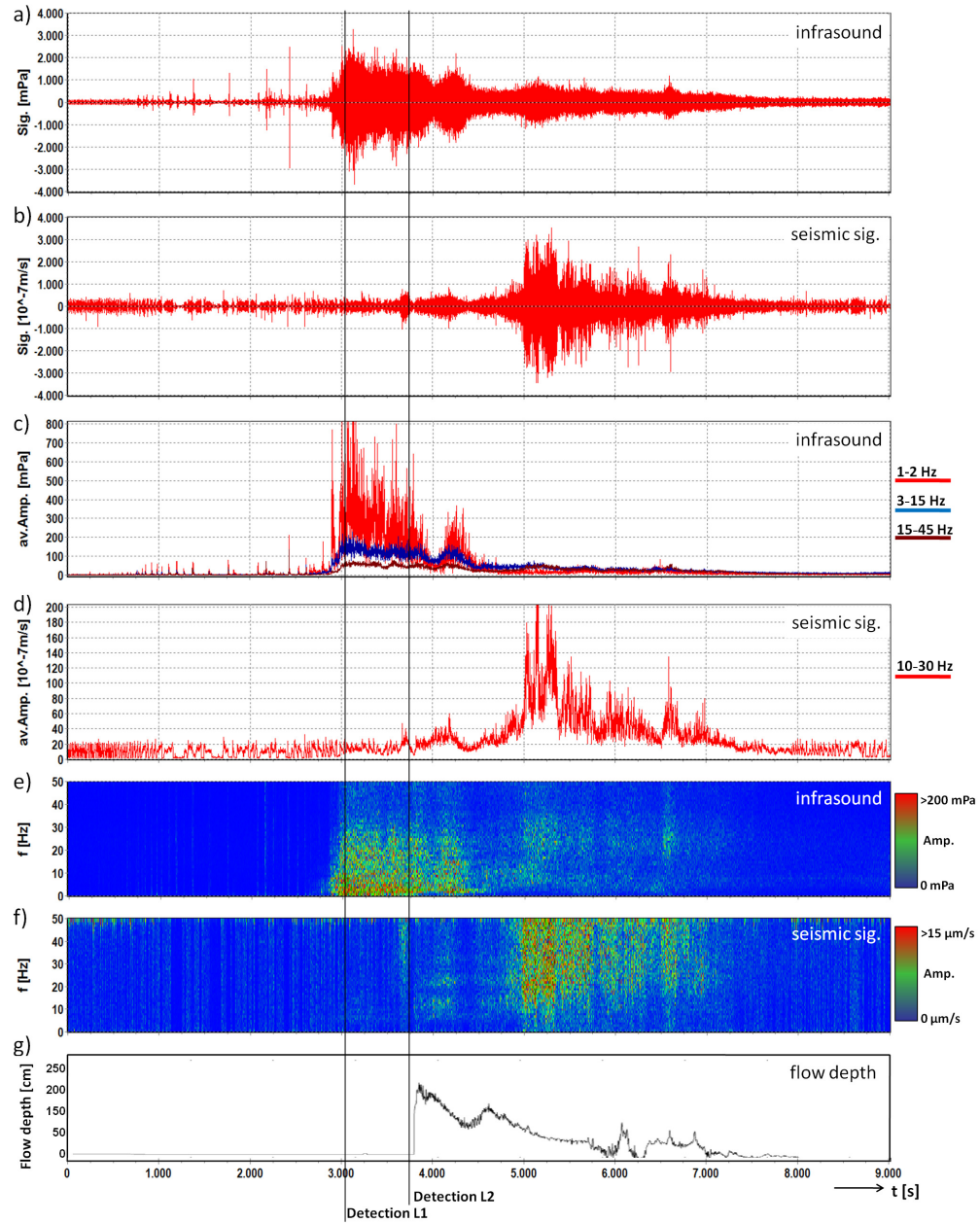

Figure 5. Infrasound and seismic data of the mudflow monitored at the Marderello test site on 9 August 2015. Signals are represented with a common base of time. (a) infrasound time series; (b) seismogram; (c) average amplitude of the three frequency bands of the infrasound signal; (d) average amplitude of the frequency band of the seismic signal; (e) running spectrum of the infrasound signal; (f) running spectrum of the seismic signal; (g) flow depth ( $70 \mathrm{~m}$ downstream); lines: time of first detection for Levels 1 and 2.

The largest amplitudes of the infrasound signal occur at $3 \mathrm{~Hz}$ with $749 \mathrm{mPa}$ and the maximum amplitude of the seismic signals was recorded at $23 \mathrm{~Hz}$ with $76 \mu \mathrm{m} / \mathrm{s}$. The detection algorithm detects 
this event at $3048 \mathrm{~s}$ for Level 1 and $3688 \mathrm{~s}$ for Level 2. We use the flow height recorded by the ultrasonic gauge around $70 \mathrm{~m}$ downstream of the detection system and adapt this point in time according to the distance between the monitoring stations and the estimated velocity of the mudflow, to estimate the event arrival at the detection system at $3690 \mathrm{~s}$. This results in an early detection time of $642 \mathrm{~s}$ at Level 1 and $2 \mathrm{~s}$ at Level 2. This long early detection time for Level 1 can be achieved due to the low flow velocity of this mudflow.

\subsection{Illgraben}

The Illgraben in Canton Vallis is the most active debris flow catchment in Switzerland. It has a catchment area of $9.5 \mathrm{~km}^{2}$ and extends from the summit of the Illhorn at $2716 \mathrm{~m}$ a.s.l. down to the Rhône valley at $610 \mathrm{~m}$ a.s.l. (Figure 6). The steep slopes in the upper catchment area and the highly fractured bedrock provoke frequent landslides and rockfalls, which results in abundant sediment deposits in the channel $[35,36]$. Due to effectively focused water runoff in the upper catchment area, these deposits lead to frequent debris flows and debris floods with an annual sediment discharge of several hundred thousand metric tons [37]. On average, three to five debris flows and debris floods are observed every year [38,39]. Since 2015, two of our detection systems have been installed at the Illgraben catchment. One of them is placed in the upper catchment area directly at the canyon rim (Station 1 in Figure 6a). This station is equipped with a Chaparral infrasound sensor and a SG-5 geophone. The other station (Station 2) is located down in the valley close to the channel mouth at check dam 27 near the football field. This station comprises an Electret microphone and a SM-6 geophone.
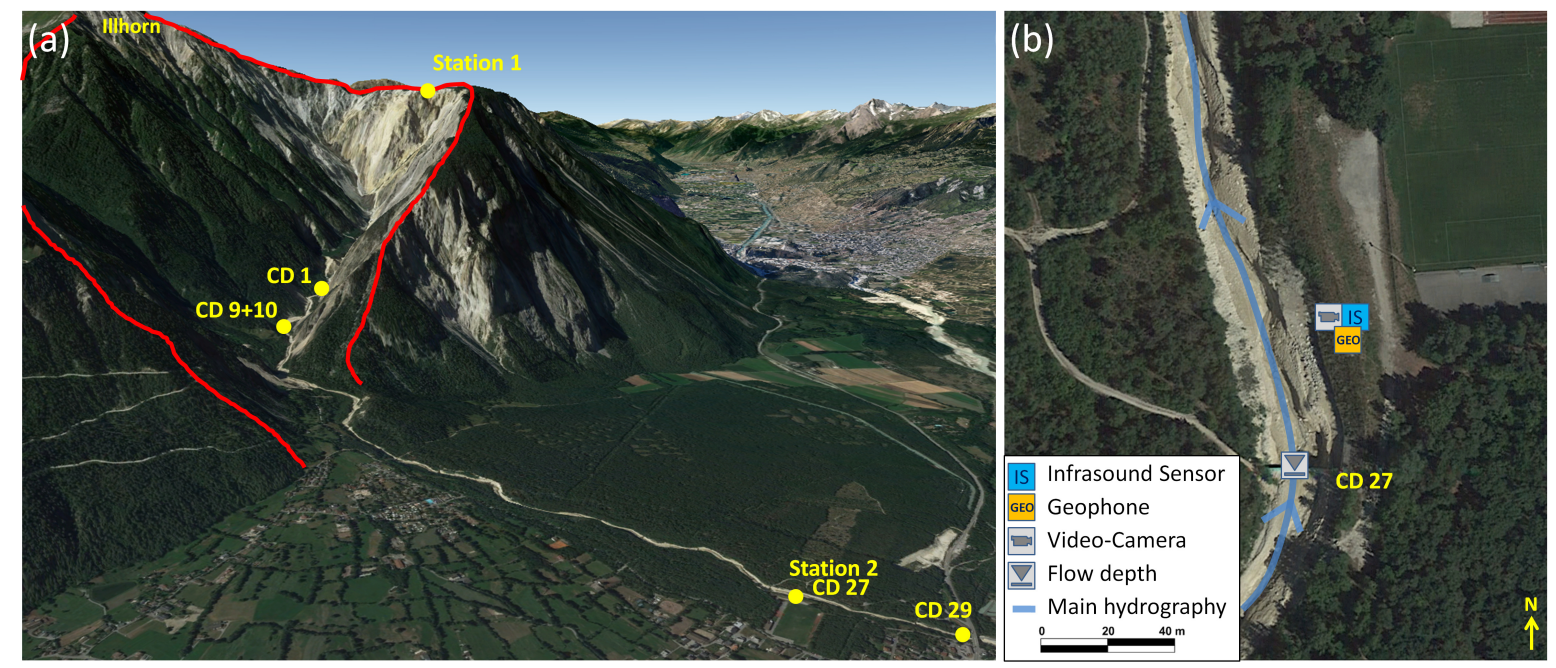

Figure 6. (a) overview of the test site Illgraben (red line: catchment area); (b) closer view of the monitoring station 2 and sensor setup (Source: Google Maps).

The debris flow illustrated here was recorded on 22 July 2015. Based on the installed measurement system [37], the event was classified as a small-sized debris flow with a total volume of $8700 \mathrm{~m}^{3}$, a peak discharge of $17 \mathrm{~m}^{3} / \mathrm{s}$ and a front velocity of around $2 \mathrm{~m} / \mathrm{s}$. Figure 7 shows the seismic and infrasound signals recorded at the Station 2 in the valley. The maximum infrasound amplitude of this event with $567 \mathrm{mPa}$ occurred at $5 \mathrm{~Hz}$, the maximum seismic amplitude of $119 \mu \mathrm{m} / \mathrm{s}$ was registered at $15 \mathrm{~Hz}$ and the event duration was approximately $3500 \mathrm{~s}$. The high amplitude spikes in the first part of the infrasound signal (<2500 s) may be caused by cultural noise or a thunderstorm. The debris flow was detected by this station at $2462 \mathrm{~s}$ for Level 1 and $2617 \mathrm{~s}$ for Level 2 . This results in an early detection time of $138 \mathrm{~s}$ (Level 1) before the event passes the sensor site (at $2600 \mathrm{~s}$ ) and for Level 2 the detection occurred $17 \mathrm{~s}$ after the passing. 

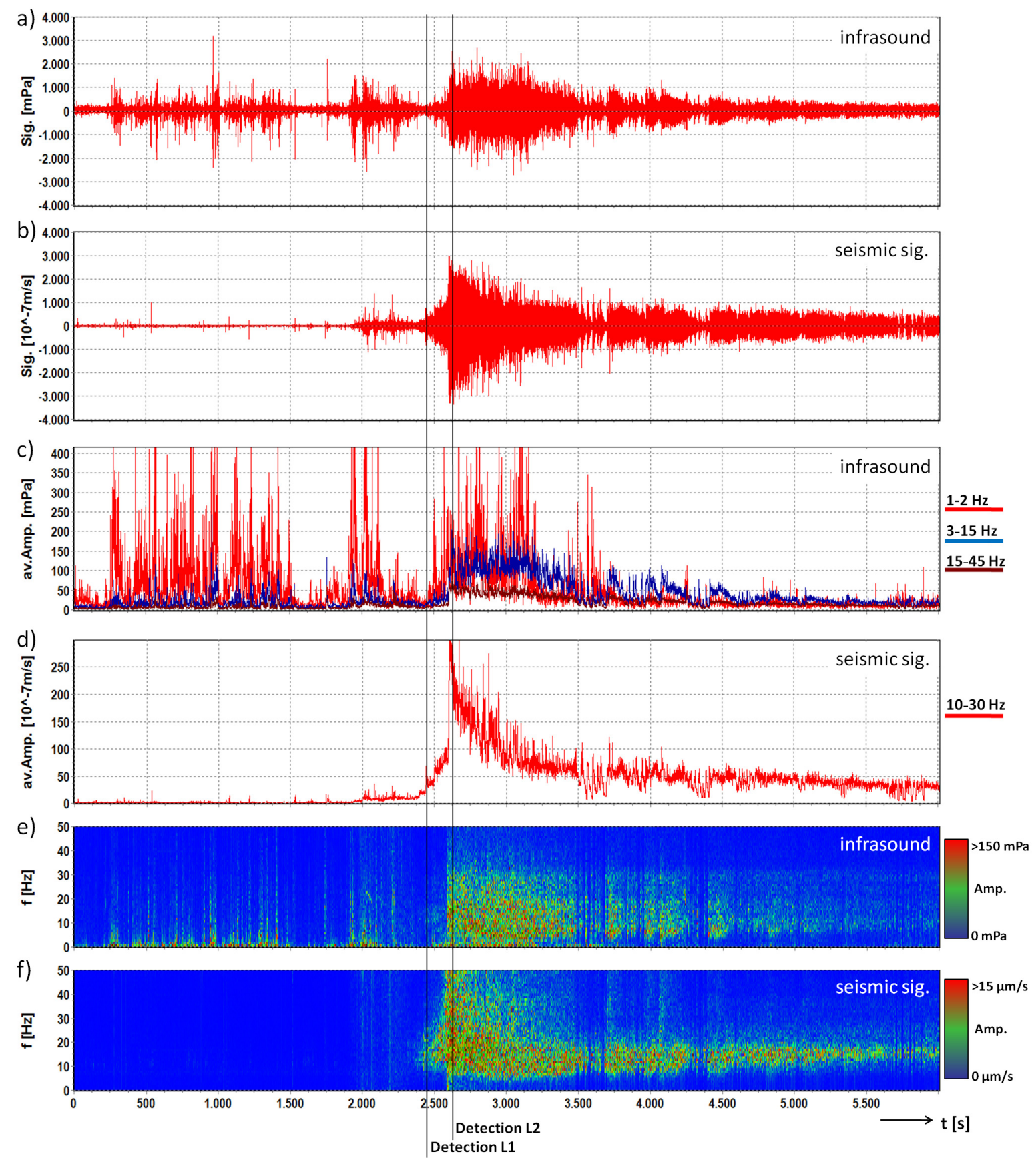

Figure 7. Infrasound and seismic data of the debris flow monitored at the Illgraben test site on 22 July 2015 at Station 2. Signals are represented with a common base of time. (a) infrasound time series; (b) seismogram; (c) average amplitude of the three frequency bands of the infrasound signal; (d) average amplitude of the frequency band of the seismic signal; (e) running spectrum of the infrasound signal; (f) running spectrum of the seismic signal; lines: time of first detection for Levels 1 and 2.

The existing early warning system at Illgraben (located at Check Dam 1 (CD 1), Check Dam 9 and 10 (CD $9+10)$, Check Dam 27 (CD 27) as well as at Check Dam 29 (CD 29) in Figure 6a; Ref. [39] provides a longer early warning time (up to several thousand seconds); however, that installation uses geophones installed at relatively exposed locations on the check dams in the channel as well as stage sensors (radar) suspended above the channel, and it relies on the mobile telephone network to transfer the alarms to warning lamps installed at several locations downstream. The system we describe here can be positioned at a safe distance from the channel. It may be possible to increase the early warning time by 
installing additional sensors closer to the source area, e.g., at the location of the detection sensors used by the Illgraben system, or by installing detection systems at each vulnerable channel crossing location. However, a more detailed comparison with the existing Illgraben early warning system is beyond the scope of this manuscript.

This debris flow was also detected at the upper Station 1. However, at this station, it has a different seismic/infrasound signature (Figure 8 ). The first part of the signal (1000s to $1800 \mathrm{~s}$ ) recorded at the Station 1 may have been caused by the initial process, which may have been a landslide in the upper catchment. This was not registered by the infrasound sensor at Station 2 in the valley because the infrasound was shielded by the mountain ridge. The second part (2200 s to $3400 \mathrm{~s}$ ) of the infrasound signal may have been produced by the subsequent debris flow. This signal is also recorded later at Station 2. We suggest that the reason for the low-frequency infrasound signal recorded at Station 1 of the second part of the debris flow might be the frequency-dependency of atmospheric attenuation absorbing high-frequency sound more than low-frequency sound [15]. In contrast to the results of [40], which showed that the seismic signals of mass movements can be detected over the entire length of the channel, the seismic signals of the first time section could be only detected at Station 1 and the seismic signal of the debris flow was registered only at Station 2 . We suggest that the geophones used are not sensitive enough to register the signals with such high magnitudes from sources at greater distances.

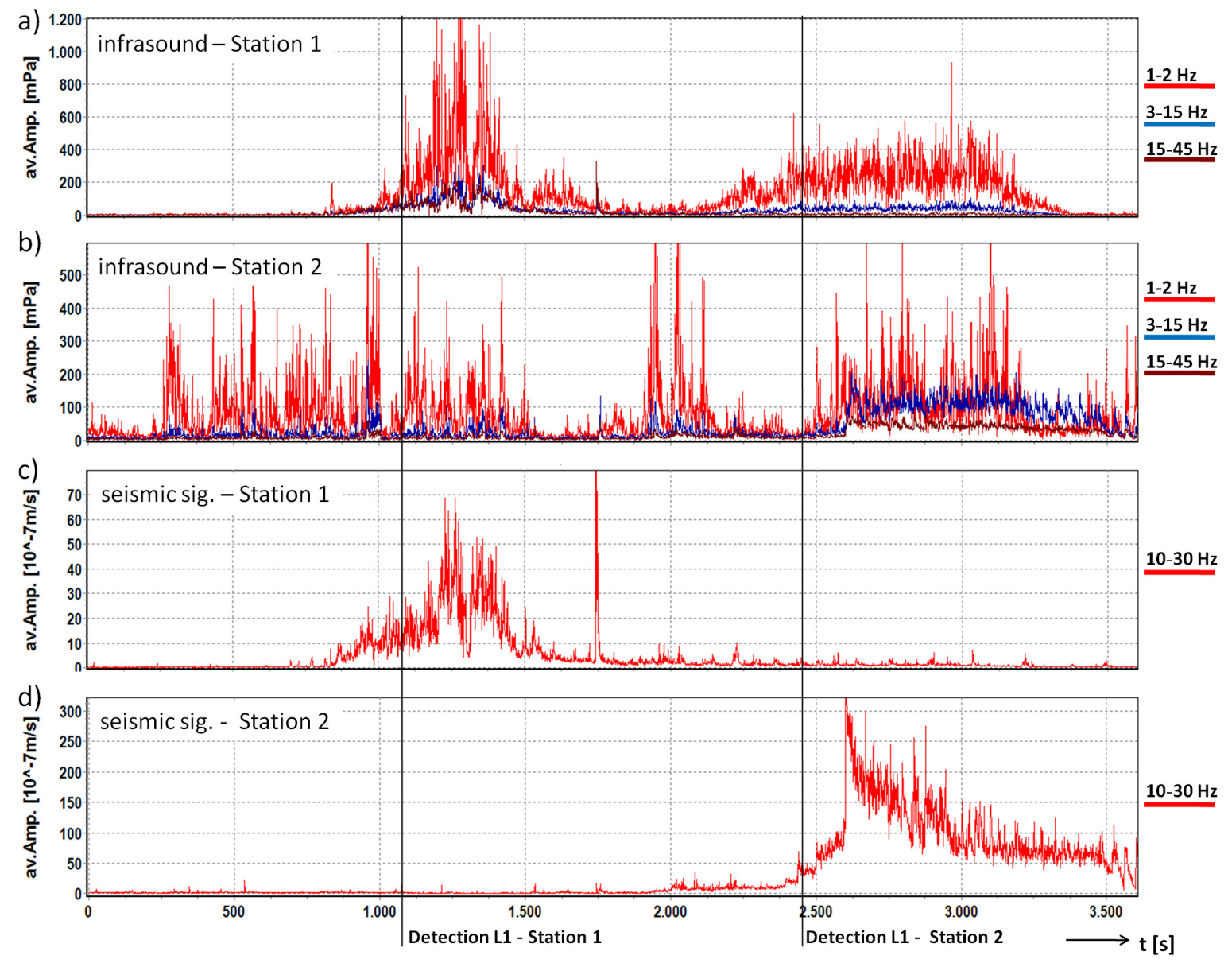

Figure 8. Comparison of the Infrasound and seismic data from the debris flow on 22 July 2015 at Stations 1 and 2 in the Illgraben catchment. Signals are represented with a common base of time. (a) average amplitude of the three frequency bands of the infrasound signal at Station 1; (b) average amplitude of the three frequency bands of the infrasound signal at Station 2; (c) average amplitude of the frequency band of the seismic signal at Station $1 ;(\mathbf{d})$ average amplitude of the frequency band of the seismic signal at Station 2; lines: time of first detection for Level 1 at Stations 1 and 2. 
This example also shows that an installation from this system in the upper catchment area can identify initial processes and thereby significantly increase the early warning times compared to the setup down close to the channel. On the other hand, since the setup at Station 1 did not register all events, a combination of one station in the starting area and one in a lower part of the channel might offer the best solution.

\section{Results and Discussion}

\subsection{Evaluation of the Detection Algorithm}

For the evaluation of the detection algorithm, the numbers are analyzed from the registered events, false alarms and missed events for all test sites from 2013 to 2016 (Table 3). The events are divided into two different types: higher discharge with sediment transport and debris floods, and debris flows. To categorize the different events, several methods such as video or flow-depth measuring are used, but the available data did not allow a reliable distinction to be made between debris flow and debris flood at all test sites, so these are found in the same group. For the detections, we distinguish between Level 1 detections, which are found primarily in the category of sediment transport processes or small debris floods, and Level 2 detections, which are usually "fully developed" debris flows and debris floods. For some detections, it was not possible to classify the signals due to missing data for evaluation or other technical problems, so they are listed separately as "non-classifiable events".

Most of the events from 2013 to 2016 were higher discharge processes (42), whereby 14 events could not be detected. Since most of the undetected events in this class were smaller ones, a detection of these events is not necessarily required, in contrast to the debris flow and debris flood events. The detection of these processes is obligatory and all 22 Level 2 events were detected and also nearly all Level 1 events were able to be detected ( 9 out of 12). During the entire operation time of 77,300 h, only seven false alarms were registered and 10 detections could not be classified clearly (Figure 9).

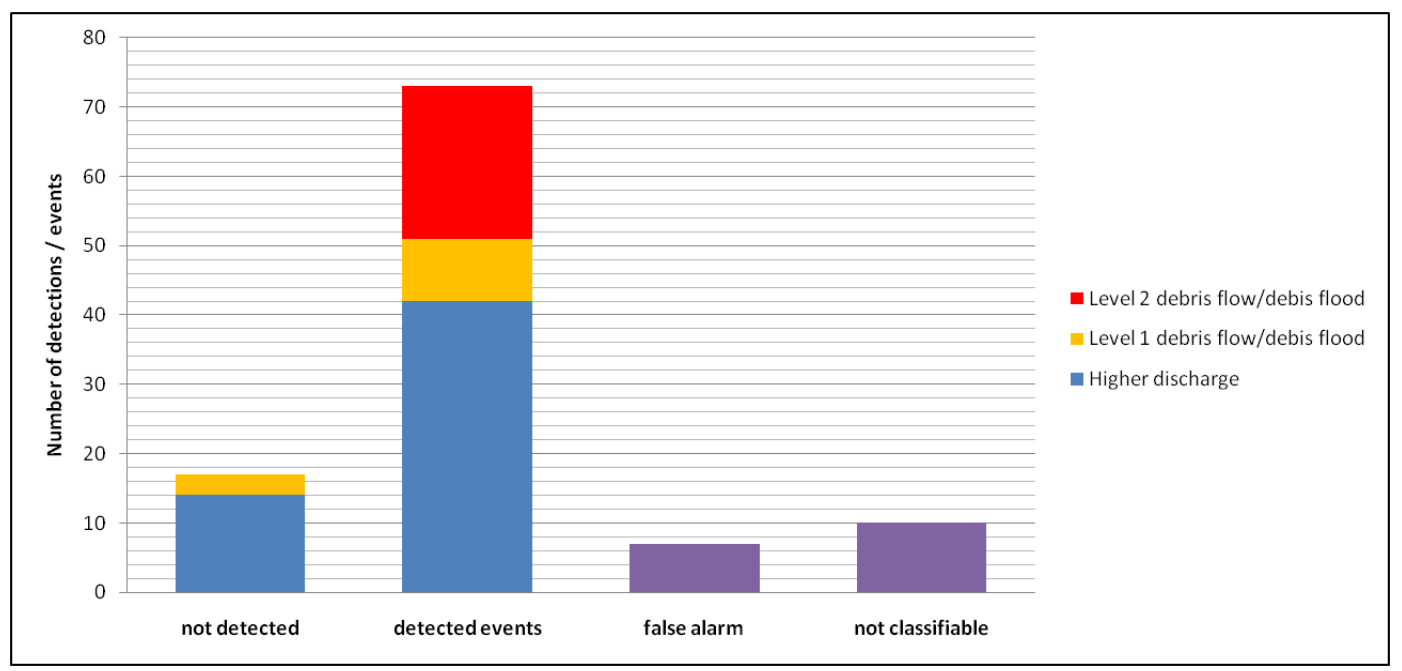

Figure 9. Summary of event detections and undetected events for all test sites from 2013 to 2016.

The time between the detection and the passing of the main surge at the sensor site (generally indicated by the maximum seismic and infrasonic amplitudes), which from here on is called "early warning time" is another factor that can be used to evaluate the system. Therefore, we compared the average early warning times of Level 2 events of the debris flow or debris flood type for all test sites (Table 4; Figure 10). 
Table 3. Events, detections and false alarms from 2013 to 2016.

\begin{tabular}{|c|c|c|c|c|c|c|c|c|c|c|c|}
\hline \multirow[b]{3}{*}{ Test Site } & \multirow[b]{3}{*}{ Year } & \multicolumn{8}{|c|}{ Debris Flow/Debris Flood } & \multirow{3}{*}{$\begin{array}{c}\text { Not } \\
\text { Classifiable }\end{array}$} & \multirow{3}{*}{$\begin{array}{c}\text { Operating } \\
\text { Hours }\end{array}$} \\
\hline & & \multicolumn{2}{|c|}{ Higher Discharge } & \multicolumn{2}{|c|}{ Level 1} & \multicolumn{2}{|c|}{ Level 2} & \multicolumn{2}{|c|}{ False Alarms } & & \\
\hline & & Detected & Not Detected & Detected & Not Detected & Detected & Not Detected & Level 1 & Level 2 & & \\
\hline \multirow{4}{*}{ Lattenbach } & 2013 & 0 & 1 & 0 & 0 & 0 & 0 & 0 & 0 & 1 & 4915 \\
\hline & 2014 & 0 & 0 & 0 & 0 & 0 & 0 & 1 & 0 & 0 & 6184 \\
\hline & 2015 & 0 & 1 & 0 & 0 & 3 & 0 & 0 & 0 & 0 & 3828 \\
\hline & 2016 & 1 & 2 & 0 & 0 & 1 & 0 & 0 & 0 & 0 & 3620 \\
\hline \multirow[t]{4}{*}{ Dristenau } & 2013 & 6 & 2 & 0 & 0 & 0 & 0 & 0 & 0 & 0 & 2202 \\
\hline & 2014 & 0 & 0 & 1 & 1 & 0 & 0 & 0 & 0 & 0 & 2832 \\
\hline & 2015 & 5 & 1 & 2 & 1 & 2 & 0 & 1 & 0 & 0 & 2907 \\
\hline & 2016 & 14 & 2 & 1 & 0 & 0 & 0 & 0 & 0 & 0 & 3191 \\
\hline \multirow{4}{*}{ Farstrinne } & 2013 & 0 & 0 & 0 & 0 & 0 & 0 & 0 & 0 & 0 & 3488 \\
\hline & 2014 & 1 & 0 & 0 & 0 & 1 & 0 & 0 & 0 & 0 & 4026 \\
\hline & 2015 & 0 & 0 & 0 & 0 & 1 & 0 & 0 & 0 & 1 & 3648 \\
\hline & 2016 & 0 & 0 & 1 & 0 & 0 & 0 & 0 & 0 & 0 & 3470 \\
\hline \multirow[t]{4}{*}{ Schüsserbach } & 2013 & 1 & 2 & 0 & 0 & 0 & 0 & 0 & 0 & 0 & 1026 \\
\hline & 2014 & 0 & 0 & 0 & 0 & 0 & 0 & 0 & 0 & 0 & 1365 \\
\hline & 2015 & 0 & 0 & 2 & 0 & 0 & 0 & 0 & 0 & 0 & 2227 \\
\hline & 2016 & 0 & 1 & 0 & 0 & 2 & 0 & 0 & 0 & 0 & 3470 \\
\hline \multirow[t]{3}{*}{ Wartschenbach } & 2013 & 1 & 1 & 0 & 0 & 0 & 0 & 0 & 0 & 0 & 1771 \\
\hline & 2015 & 2 & 0 & 0 & 0 & 0 & 0 & 1 & 0 & 4 & 2662 \\
\hline & 2016 & 2 & 0 & 0 & 0 & 0 & 0 & 0 & 0 & 1 & 3473 \\
\hline \multirow[t]{2}{*}{ Illgraben } & 2015 & 2 & 0 & 0 & 0 & 4 & 0 & 1 & 0 & 0 & 2161 \\
\hline & 2016 & 1 & 0 & 0 & 0 & 5 & 0 & 1 & 0 & 0 & 2705 \\
\hline \multirow[t]{2}{*}{ Gadira } & 2015 & 0 & 0 & 1 & 0 & 0 & 0 & 0 & 0 & 0 & 2351 \\
\hline & 2016 & 1 & 0 & 1 & 0 & 1 & 0 & 2 & 0 & 0 & 2804 \\
\hline \multirow[t]{2}{*}{ Marderello } & 2015 & 2 & 1 & 0 & 1 & 1 & 0 & 0 & 0 & 1 & 3023 \\
\hline & 2016 & 3 & 0 & 0 & 0 & 1 & 0 & 0 & 0 & 2 & 2201 \\
\hline \multirow[t]{2}{*}{ Lueger Hausgraben } & 2016 & 0 & 0 & 0 & 0 & 0 & 0 & 0 & 0 & 0 & 1750 \\
\hline & SUM: & 42 & 14 & 9 & 3 & 22 & 0 & 7 & 0 & 10 & 77,300 \\
\hline
\end{tabular}


Table 4. Average early warning times for Level 2 debris flow/debris flood at different test sites.

\begin{tabular}{cccc}
\hline & $\begin{array}{c}\text { Average Early Warning Time } \\
\text { Level 1 (s) }\end{array}$ & $\begin{array}{c}\text { Average Early Warning Time } \\
\text { Level 2 (s) }\end{array}$ & $\begin{array}{c}\text { Number of } \\
\text { Events }\end{array}$ \\
\hline Lattenbach & 17 & 1 & 5 \\
Farstrinne & 87 & 15 & 2 \\
Dristenau & 13 & -168 & 4 \\
Schüsserbach & 28 & 0 & 2 \\
Gadria & 120 & 79 & 3 \\
Illgraben & 197 & 57 & 8 \\
Marderello & 511 & 63 & 2 \\
\hline
\end{tabular}

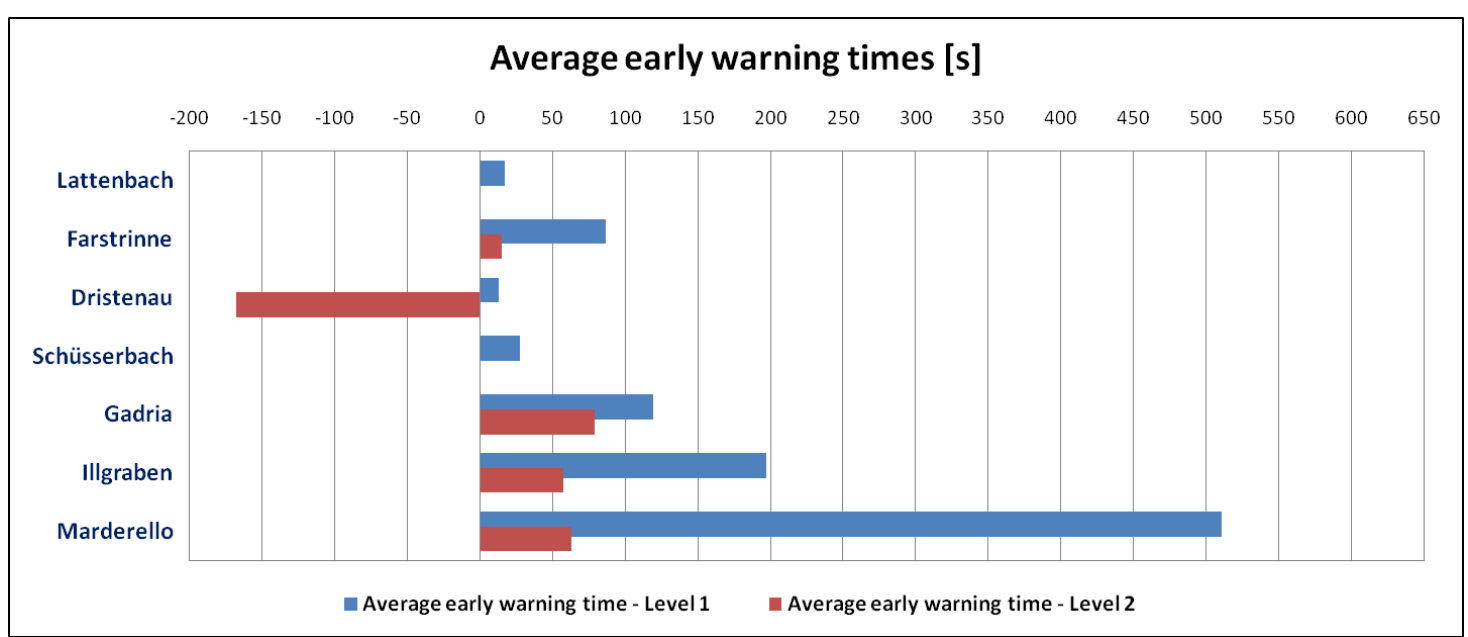

Figure 10. Overview average early warning times for all events listed in Table 4.

This evaluation shows the wide variance between the different test sites, whereby the average early warning times at Marderello are the longest at nearly ten minutes (at Level 1) compared to the average early warning times at Dristenau, where events are detected only a few seconds before passing. The Level 2 detections are closer to the passing of the main surge for most recorded events and, at the Dristenau test site, this time is even negative. This late Level 2 detection time is caused mainly by the smaller event size at this test site, where Level 2 detections are often results of later surges. Another reason is that, at the Dristenau test site, the position of the monitoring station is close to the valley end where events are generated, as described in [23].

\subsection{Magnitude Estimation}

We also estimated the event size based on the infrasound and seismic data. The infrasound and seismic energy correlates passably with the discharge of an event (e.g., [41]), so we compared the maximum infrasound and/or seismic amplitudes with the peak discharge of an event (Figure 11). The values for peak discharge and total volume used for this analysis are from Level 2 events at the Lattenbach, Gadria and Illgraben test sites (Table 5) and are calculated based on flow height measurements and velocity estimations. Since all monitoring stations used for this study are rather close to the channel (between 10 and $20 \mathrm{~m}$ ) and the distances are nearly the same at every test site, we neglected attenuation of the signals in the air or in the ground, geometric spreading and the influence of topography or geology. 
Table 5. Peak discharge and total volume.

\begin{tabular}{cccc}
\hline Test Site & Event Date & $\begin{array}{c}\text { Peak Discharge } \\
\left(\mathbf{m}^{3} \mathbf{s}\right)\end{array}$ & $\begin{array}{c}\text { Total Volume } \\
\mathbf{( \mathbf { m } ^ { 3 } \mathbf { ) }}\end{array}$ \\
\hline Lattenbach & 9 August 2015 & 50 & 11,500 \\
& 10 August 2015 & 69 & 18,500 \\
& 16 August 2015 & 12 & 5000 \\
& 10 September 2016 & 158 & 46,000 \\
\hline Gadria & 15 July 2014 & na & 10,500 \\
& 8 June 2015 & na & 9850 \\
& 12 July 2016 & na & 1500 \\
\hline Illgraben & 22 July 2015 & 17 & 8700 \\
& 10 August 2015 & 7 & 6100 \\
& 14 August 2015 & 7 & 25,000 \\
& 15 August 2015 & 3 & 2000 \\
& 12 July 2016 & 15 & 10,000 \\
& 12 July 2016 & 65 & 60,000 \\
& 22 July 2016 & $50-90$ & $>10,000$ \\
& 9 August 2016 & 29 & $<10,000$ \\
\hline
\end{tabular}

This analysis shows that, for peak discharge, the use of infrasound amplitudes with a power curve fitting offers a good approach to finding an initial relationship between the recorded signals and this event parameter. This curve fitting provides a $R^{2}$ of 0.955 for peak discharge. The approximation for peak discharge $Q_{\text {peak }}$ (in $\mathrm{m}^{3} / \mathrm{s}$ ) can be calculated based on the maximum infrasound amplitudes $A_{\mathrm{IS}(\max )}$ (in $\mathrm{mPa}$ ) according to Equation (8). The marked outlier in the upper range of the maximum amplitudes is produced by the event on 10 August 2015 at the Illgraben test site and has not been included in the curve fitting process:

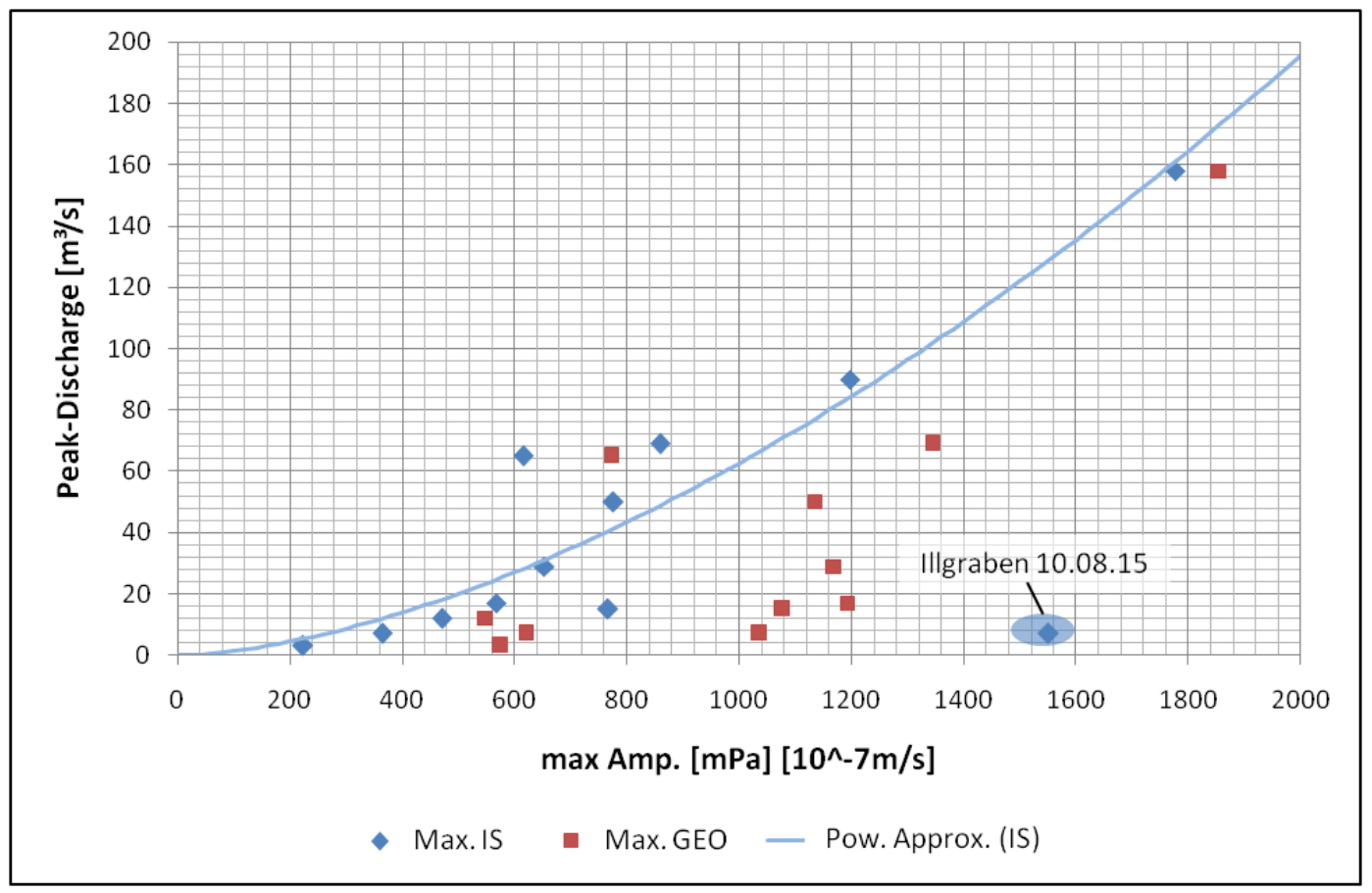

Figure 11. Peak discharge over maximum seismic (Max GEO) and infrasound amplitudes (Max IS) and the approximation based on infrasound data (Pow. Approx.).

$$
Q_{\text {peak }}=0.000732 A_{\mathrm{IS}(\max )}^{1.644}
$$


For an estimation of the total volume, we integrate the discharge calculated with the relationship for peak discharge (Equation (8)) over the entire detection time of an event. Figure 12 compares the calculated values (vertical axis) for peak discharge and total volume to the observed values (horizontal axis). The line represents the one-to-one relationship.
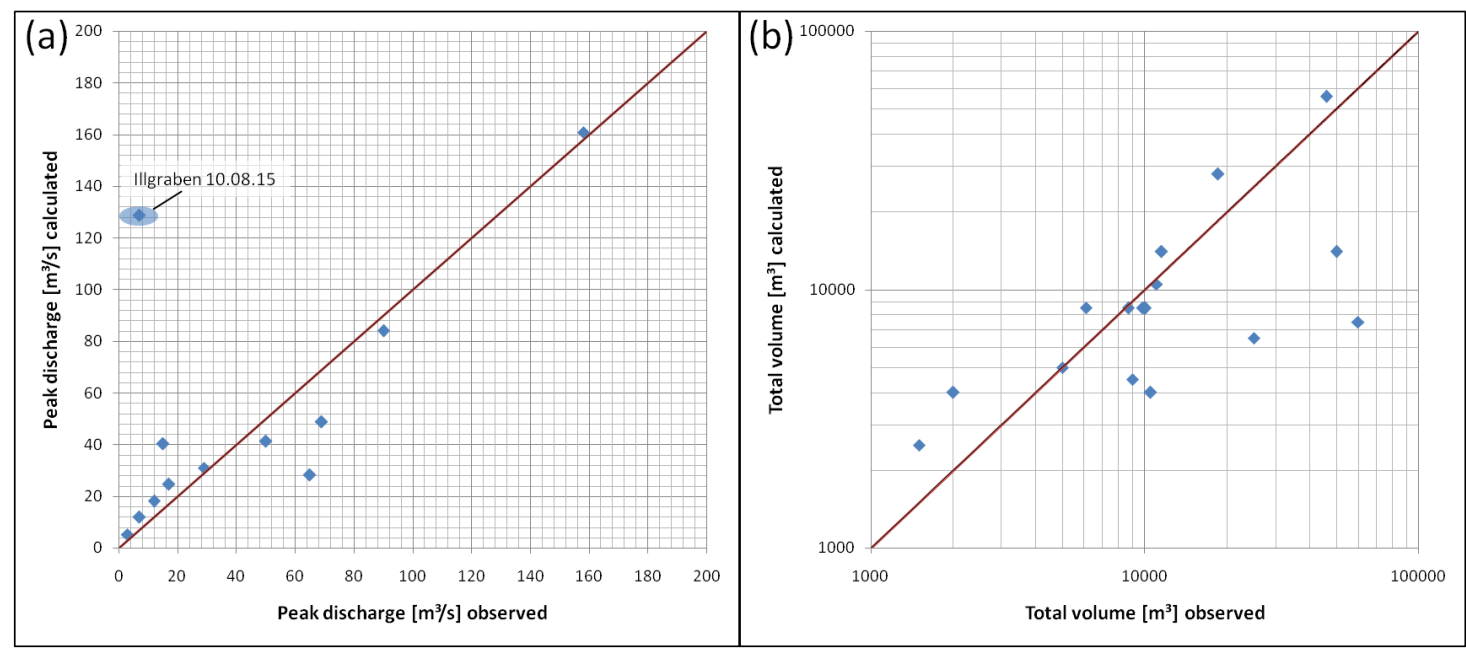

Figure 12. (a) comparison of the calculated peak discharge to the observed values; (b) comparison of the calculated total volume to the observed volume.

Both diagrams suggest that it may be possible to obtain first-order estimates of the peak discharge and the total volume for debris flows and debris floods at different sites based on the infrasound amplitudes. Calculation of the peak discharge based on infrasound data offers a good approximation $\left(R^{2}=0.88\right)$, but, for the calculation of the total volume, this method shows a wide variance $\left(R^{2}=0.27\right)$. Because the total volume is estimated by the sum over the event duration, this duration has to be defined based on the seismic and infrasound data, which is done by applying the detection criteria. Thus, the amplitude thresholds for the detection criteria also have an influence on the event duration and on the total volume estimation.

To evaluate this method for the magnitude estimation, we analyzed an event that occurred on 9 August 2015 at the Lattenbach test site. This debris flow with a total volume of $11,600 \mathrm{~m}^{3}$ and a peak discharge of $50 \mathrm{~m}^{3} / \mathrm{s}$ had a maximum infrasound amplitude of $776 \mathrm{mPa}$ at $16 \mathrm{~Hz}$ and a maximum seismic amplitude of $113 \mu \mathrm{m} / \mathrm{s}$ at $29 \mathrm{~Hz}$. If the method for the discharge estimation is applied to the infrasound signal, the peak discharge is calculated as $41 \mathrm{~m}^{3} / \mathrm{s}$ and the total volume as $13,430 \mathrm{~m}^{3}$. At the Lattenbach monitoring site, a 2D Laser scanner can be used in combination with a debris flow Puls-Doppler Radar (IBTP-Koschuch, [42]) for surface velocity to calculate, with a good degree of accuracy, the discharge of debris flows with a time resolution of one second during the whole event duration [43]. Figure 13 compares the discharge and total volume estimate based on the infrasound signal to the measured discharge. The total volume can be determined by summing up the discharge during the event time. This method results in an underestimate of the discharge based on the infrasound signal for the first time section of the debris flow and an overestimation in the second part of the debris flow duration.

This analysis showed that it is possible to achieve a rough estimate of peak discharge and total volume based on infrasound signals; nevertheless, further research and additional data on different events are necessary to develop a robust method for magnitude identification. 


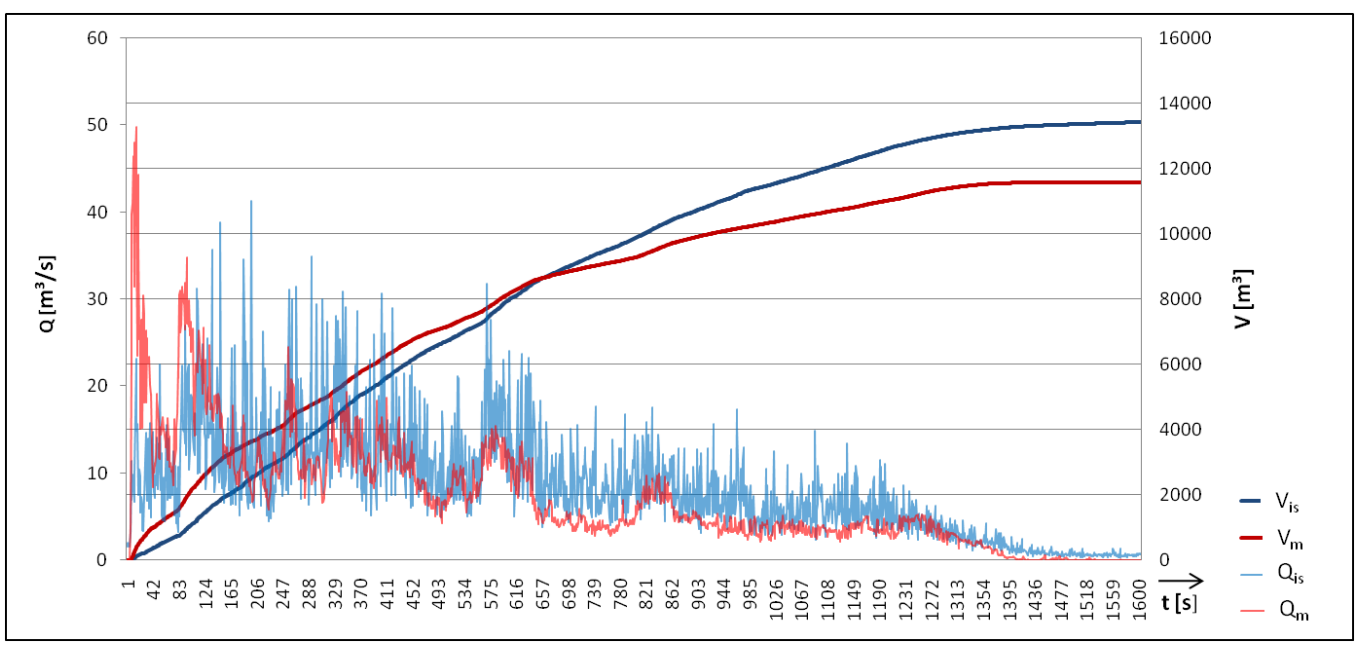

Figure 13. Calculated discharge $\left(\mathrm{Q}_{\mathrm{is}}\right)$ and calculated volume $\left(\mathrm{V}_{\mathrm{is}}\right)$ based on infrasound data compared to measured discharge $\left(\mathrm{Q}_{\mathrm{m}}\right)$ and measured volume $\left(\mathrm{V}_{\mathrm{m}}\right)$ of the debris flow at Lattenbach on 9 August 2015.

\section{Conclusions}

This paper demonstrates the potential for combining seismic and infrasound measurements to promote the development of an automatic rapid detection and identification system for debris-flow-related disasters. The proposed detection system based on one infrasound sensor, one co-located geophone and a microcontroller is inexpensive, portable and easy to install and can be extended to an early warning system for different kinds of alpine mass movements. As such, the combination of infrasound and seismic sensors increases detection probability and reduces the frequency of false alarms. It was possible to detect automatically all larger debris flows and debris floods in the period from 2013 to 2016 at nine different test sites, while only seven false alarms were registered in this time period. However, sensor equipment and installation location have to be chosen carefully (e.g., no shielding of infrasound, consolidated soil for the geophone, right position along the channel) and parameters of the detection algorithm may have to be adapted to the particular application and the background noise of the site. Initial analyses of different event types and different magnitudes have shown a dependency of the peak frequency range on the viscosity and a relation of the maximum infrasound and seismic amplitudes to the event magnitude. For this reason, a first estimate of the maximum discharge and the total volume based on the seismic or infrasound data is possible, whereby the infrasound amplitude seems to be a better approach for such a magnitude estimate. However, further research based on large databases of different well categorized events at different test sites is necessary for reliable event identification. An estimate of the process velocity could increase the accuracy of the identification of the magnitude and type since the infrasound and seismic signal signature also depends on the process velocity. Thus, as a further step, a method for velocity estimation would be included, which can be done by extending the system with an additional seismic of the infrasound sensor.

Author Contributions: A.S. proposed the idea, developed the detection system and performed the tests. F.W. and A.S. analyzed the data. B.W.M. contributed data from the Illgraben test site. J.H. supervised the research work and contributed data from the Lattenbach test site. A.S. wrote the paper and all authors participated in the organization of the paper.

Acknowledgments: We thank Velio Coviello (Free University of Bozen-Bolzano) and Laura Turconi (Research Institute for Geo-hydrological Protection, Turin (CNR IRPI)) for data from the Marderello test site and support in the field and Susan Braun-Clarke for proofreading of this manuscript. Andreas Schimmel received financing from the Austrian Academy of Science (ÖAW) Earth System Sciences (ESS) project "Identification of sediment-related disaster based on seismic and acoustic signals" (MM-Identification). The salary of Fabian Walter was paid by the Swiss National Science Foundation (grant PP00P2_157551). Article processing charges supported by the BOKU Vienna Open Access Publishing Fund. 
Conflicts of Interest: The authors declare no conflict of interest.

\section{References}

1. Hunger, O.; Evans, S.G.; Bovis, M.J.; Hutchinson, J.N. A review of the classification of landslides of the flow type. Environ. Eng. Geosci. 2001, 7, 221-238. [CrossRef]

2. Coussot, P.; Laigle, D.; Arattano, M.; Deganutti, A.M.; Marchi, L. Direct determination of rheological characteristics of debris flow. J. Hydraul. Eng. 1998, 124, 865-868. [CrossRef]

3. Kean, J.W.; Coe, J.A.; Coviello, V.; Smith, J.B.; McCoy, S.W.; Arattano, M. Estimating rates of debris flow entrainment from ground vibrations. Geophys. Res. Lett. 2015, 42, 6365-6372. [CrossRef]

4. Tsai, V.C.; Minchew, B.; Lamb, M.P.; Ampuero, J.P. A physical model for seismic noise generation from sediment transport in rivers. Geophys. Res. Lett. 2012, 39, 1944-8007. [CrossRef]

5. Biescas, B.; Dufour, F.; Furdada, G.; Khazaradze, G.; Suriñach, E. Frequency content evolution of snow avalanche seismic signals. Surv. Geophys. 2003, 24, 447-464. [CrossRef]

6. Huang, C.-J.; Yin, H.-Y.; Chen, C.-Y.; Yeh, C.-H.; Wang, C.-L. Ground vibrations produced by rock motions and debris flows. J. Geophys. Res. Earth Surf. 2007, 112, F02014. [CrossRef]

7. Vilajosana, I.; Suriñach, E.; Abellán, A.; Khazaradze, G.; Garcia, D.; Llosa, J. Rockfall induced seismic signals: Case study in Montserrat, Catalonia. Nat. Hazards Earth Syst. Sci. 2008, 8, 805-812. [CrossRef]

8. Arattano, M.; Marchi, L.; Cavalli, M. Analysis of debris-flow recordings in an instrumented basin: Confirmations and new findings. Nat. Hazards Earth Syst. Sci. 2012, 12, 679-686. [CrossRef]

9. Arattano, M.; Abancó, C.; Coviello, V.; Hürlimann, M. Processing the ground vibration signal produced by debris flows: The methods of amplitude and impulses compared. Comput. Geosci. 2014, 73, 17-27, ISSN 0098-3004. [CrossRef]

10. Abancó, C.; Hürlimann, M.; Fritschi, B.; Graf, C.; Moya, J. Transformation of ground vibration signal for debris-flow monitoring and detection in alarm systems. Sensors 2012, 12, 4870-4891. [CrossRef] [PubMed]

11. Coviello, V.; Arattano, M.; Turconi, L. Detecting torrential processes from a distance with a seismic monitoring network. Nat. Hazards 2015, 78, 2055-2080. [CrossRef]

12. Walter, F.; Burtin, A.; McArdell, B.W.; Hovius, N.; Weder, B.; Turowski, J.M. Testing seismic amplitude source location for fast debris-flow detection at Illgraben, Switzerland. Nat. Hazards Earth Syst. Sci. 2017, 17, 939-955. [CrossRef]

13. Chou, H.T.; Cheung, Y.L.; Zhang, S. Calibration of Infrasound Monitoring System and Acoustic Characteristics of Debris-Flow Movement by Field Studies. In Proceedings of the Fourth International Conference on Debris-Flow Hazards Mitigation: Mechanics, Prediction, and Assessment, Chengdu, China, 10-13 September 2007; Chen, C.L., Major, J.J., Eds.; Millpress: Rotterdam, The Netherlands, 2007; pp. 571-580.

14. Kogelnig, A.; Hübl, J.; Suriñach, E.; Vilajosana, I.; McArdell, B.W. Infrasound produced by debris flow: Propagation and frequency content evolution. Nat. Hazards 2014, 70, 1713-1733. [CrossRef]

15. Pilger, C.; Bittner, M. Infrasound from tropospheric sources: Impact on mesopause temperature? J. Atmos. Sol. Terr. Phys. 2009, 71, 816-822. [CrossRef]

16. Kogelnig, A. Development of Acoustic Monitoring for Alpine Mass Movements. Ph.D. Thesis, University of Natural Resources and Life Sciences (BOKU), Institute of Mountain Risk Engineering, Vienna, Austria, 2012.

17. Chou, H.T.; Chang, Y.L.; Zhang, S.X. Acoustic signals and geophone response of rainfall-induced debris flows. J. Chin. Inst. Eng. 2010, 36, 335-347. [CrossRef]

18. Liu, D.; Leng, X.; Wei, F.; Zhang, S.; Hong, Y. Monitoring and recognition of debris flow infrasonic signals. J. Mt. Sci. 2015, 12, 797-815. [CrossRef]

19. Suriñach, E.; Kogelnig, A.; Vilajosana, I.; Hübl, J.; Hiller, M.; Dufour, F. Incoporación del la señal de infrasonido a la detección y estudio de aludes de nieve y flujostorrenciales. In Proceedings of the VII Simposio Nacional sobre Taludes y Laderas Inestables, Barcelona, Spain, 27-30 October 2009.

20. Hübl, J.; Schimmel, A.; Kogelnig, A.; Suriñach, E.; Vilajosana, I.; McArdell, B.W. A review on acoustic monitoring of debris flow. Int. J. Saf. Secur. Eng. 2013, 3, 105-115, ISSN 2041-9031. [CrossRef]

21. Leprette, B.; Martin, N.; Glangeaud, F.; Navarre, J.P. Three-component signal recognition using time, time-frequency, and polarization information-application to seismic detection of avalanches. IEEE Trans. Signal Process. 1998, 46, 83-102. [CrossRef] 
22. Bessason, B.; Eiríksson, G.; Thórarinsson, Ó.; Thórarinsson, A.; Einarsson, S. Automatic detection of avalanches and debris flows by seismic methods. J. Glaciol. 2007, 53, 461-472. [CrossRef]

23. Schimmel, A.; Hübl, J. Automatic detection of debris flows and debris floods based on a combination of infrasound and seismic signals. Landslides 2016, 13, 1181-1196, ISSN 1612-510X. [CrossRef]

24. Schimmel, A.; Hübl, J.; Koschuch, R.; Reiweger, I. Automatic detection of avalanches: Evaluation of three different approaches. Nat. Hazards 2017, 87, 83-102. [CrossRef]

25. SparqEE. Available online: www.SparqEE.com (accessed on 21 May 2018)

26. freeRTOS. Available online: www.freertos.org (accessed on 21 May 2018)

27. MAMODIS. Available online: ian-infrasonic.boku.ac.at (accessed on 21 May 2018)

28. Rabiner, L.R.; Schafer, R.W.; Rader, C.M. The chirp z-transform algorithm and its application. Bell Syst. Tech. J. 1969, 48, 1249-1292. [CrossRef]

29. Schimmel, A.; Hübl, J. Approach for an Early Warning System for Debris Flow Based on Acoustic Signals. In Engineering Geology for Society and Territory-Volume 3: River Basins, Reservoir Sedimentation and Water Resources; Lollino, G., Arattano, M., Rinaldi, M., Giustolisi, O., Marechal, J.-C., Grant, G.E., Eds.; Springer: Berlin, Germany, 2015; Volume 3, pp. 55-58. [CrossRef]

30. Pierson, T.C. Flow behavior of channelized debris flows, Mount St. Helens, Washington. In Hillslope Processes; Abrahams, A.D., Ed.; Allen and Unwin: Winchester, MA, USA, 2009; pp. 269-296.

31. Zhang, S.; Hong, Y.; Yu, B. Detecting infrasound emission of debris flow for warning purpose. In Proceedings of the 10. Congress Interpraevent, Riva del Garda, Italy, 24-27 May 2004.

32. Turconi, L.; De Kumar, S.; Tropeano, D.; Savio, G. Slope failure and related processes in the Mt. Rocciamelone area (Cenischia Valley, Western Italian Alps). Geomorphology 2010, 114, 115-128, ISSN 0169-555X. [CrossRef]

33. Turconi, L.; Coviello, V.; Arattano, M.; Savio, G.; Tropeano, D. Monitoring mud-flows for investigative and warning purposes: The instrumented catchment of Rio Marderello (North-Western Italy). Eng. Geol. Soc. Territ. 2015, 3, 85-90._17. [CrossRef]

34. Johnson, J.B.; Lees, J.; Yepes, H. Volcanic eruptions, lightning, and a waterfall: Differentiating the menagerie of infrasound in the Ecuadorian jungle. Geophys. Res. Lett. 2006, 33. [CrossRef]

35. Berger, C.; McArdell, B.W.; Schlunegger, F. Direct measurement of channel erosion by debris flows, Illgraben, Switzerland. J. Geophys. Res. 2011, 116, F01002. [CrossRef]

36. Bennett, G.L.; Molnar, P.; Eisenbeiss, H.; McArdell, B.W. Erosional power in the Swiss Alps: Characterization of slope failure in the Illgraben. Earth Surf. Process. Landf. 2012, 37, 1627-1640. [CrossRef]

37. Schlunegger, F.; Badoux, A.; McArdell, B.W.; Gwerder, C.; Schnydrig, D.; Rieke-Zapp, D.; Molnar, P. Limits of sediment transfer in an alpine debris-flow catchment, Illgraben, Switzerland. Quat. Sci. Rev. 2009, 28, 1097-1105, ISSN 0277-3791. [CrossRef]

38. Rickenmann, D.; Hürlimann, M.; Graf, C.; Näf, D.; Weber, D. Murgang-Beobachtungsstationen in der Schweiz. Wasser Energie Luft 2001, 93, 1-8.

39. Badoux, A.; Graf, C.; Rhyner, J.; Kuntner, R.; McArdell, B.W. A debris-flow alarm system for the Alpine Illgraben catchment: Design and performance. Nat. Hazards 2009, 49, 517-539. [CrossRef]

40. Burtin, A.; Hovius, N.; McArdell, B.W.; Turowski, J.; Vergne, J. Seismic constraints on dynamic links between geomorphic processes and routing of sediment in a steep mountain catchment. Earth Surf. Dyn. 2014, 2, 21-33. [CrossRef]

41. Hsu, L.; Finnegan, N.J.; Brodsky, E.E. A seismic signature of river bedload transport during storm events. Geophys. Res. Lett. 2011, 38, L13407. [CrossRef]

42. Koschuch, R.; Jocham, P.; Hübl, J. One year use of high-frequency RADAR technology in Alpine mass movement monitoring: Principles and performance for torrential activities. Eng. Geol. Soc. Territ. 2015, 3, 69-72.

43. Hübl, J.; Schimmel, A.; Koschuch, R. Monitoring of Debris Flows with an Improved System Setup at Lattenbach Catchment, Austria. In Advancing Culture of Living with Landslides-Diversity of Landslide Forms 4; Mikos, M., Casagli, N., Yin, Y., Sassa, K., Eds.; Springer Nature: Cham, Switzerland, 2017; p. 707, ISBN 978-3-319-53484-8 . 